\title{
Developing Radical-Digital Interventions to Tackle Loneliness Amongst the Elderly
}

Dhruv Sharma ${ }^{1}$, Lynne Blair ${ }^{2}$, Stephen Clune ${ }^{3}$

\author{
${ }^{1}$ HighWire Centre for Doctoral Training, Lancaster University, Lancaster, UK \\ d.sharma2@lancaster.ac.uk \\ ${ }^{2}$ School of Computing and Communications, Lancaster University, UK \\ 1.blair@lancaster.ac.uk \\ ${ }^{3}$ Imagination Lancaster, Lancaster University, Lancaster, UK \\ s.clune@lancaster.ac.uk
}

\begin{abstract}
Loneliness is a growing issue amongst older people and one popular approach to tackling it is by developing non-medical interventions such as befriending services, mentoring provisions, social clubs, etc. Our analysis reveals that these interventions are predominantly incremental-physical in nature and that there is a lack of radical-digital ones. In this paper we discuss the properties of digital technologies that can be potentially helpful for the elderly and we suggest that social innovation provides a robust theoretical framework to conceive radicaldigital loneliness interventions. We also draw parallels between loneliness interventions based on social innovation and the emerging 'sharing economy' in the digital world and discuss the role of third paradigm of HCI research in this area.
\end{abstract}

Keywords: Elderly, Loneliness, Interventions, The third paradigm, Radicaldigital

\section{Introduction}

Because humans are social animals, our social relationships are very important for our emotional fulfilment, behavioural adjustment and mental wellbeing [1]. Disruption to these relationships can cause exceedingly unpleasant experiences associated with insufficient discharge of the need for human intimacy, called 'loneliness' [2]. Loneliness can be equated to 'perceived isolation' [3] or can be more precisely defined as the distressing feeling that results from, and comes with, discrepancies between one's desired and actual social relationships [4, 5]. Loneliness can be severely detrimental to health and quality of life of an individual [6-8]. Frans De Waal, a leading anthropologist, has highlighted the importance of human company in our lives. He opines that, "Next to death, solitary confinement is our most extreme punishment. Our bodies and minds are not designed for lonely lives. We become hopelessly depressed in the absence of human company and our health deteriorates" [9]. Weiss refers to loneliness as a "a gnawing chronic disease without redeeming features" that can instigate depression [8]. Loneliness should not be confused with living alone as many who live alone life fully integrated as well as socially active lives [10]. However it has been observed that loneliness is more common amongst people who live alone [11-13]. 
Results from an English longitudinal study of ageing by the Office for National Statistics, UK (ONS) suggest that 25 per cent of those aged 52 and over felt lonely sometimes. An additional 9 per cent of these respondents reported that they 'often' felt lonely [14]. Therefore age-related loneliness is a major social issue as it is increasing alongside an upward global population trend which predicts that nearly $22 \%$ of the world population will be aged 60 years or over by 2050 [15]. This 'silver tsunami' [16] represents an unprecedented growth of the elderly population and is likely to exert socio-economic pressure globally in the form of healthcare needs $[17,18]$. Researchers have long discussed loneliness' close association with ageing [19-22]. They have also suggested that those over 80 years of age are more vulnerable to experiencing it $[23,24]$. Recent surveys conducted in the USA, the UK and Japan, etc. reveal this plight of the elderly as many older people report experiencing loneliness 'often' [25-27].

As a society we have been trying to tackle this seemingly impenetrable problem of loneliness amongst older adults for some time. For example, some of the strategies examined by Cattan et al. in their systematic review of interventions aimed at reducing loneliness amongst older people were developed nearly 30 years ago [7]. The fact that we are still trying to address similar (if not the same) issues at present, highlights a clear need to reflect upon our existing approach to mitigating loneliness so that we can develop more effective loneliness interventions. However, age-related loneliness is a 'complex concept' [28] and it is important to conduct rigorous research in this area to enhance our understanding of preventing, moderating or reducing loneliness amongst the elderly.

Previously we have suggested that there is an under-representation of digital technologies in loneliness interventions for the elderly [29]. This is in spite of digital technologies affording [30] several qualities that can ease age-related factors contributing to loneliness such as mobility challenges, audio-visual problems, etc. In this paper we highlight that the current thinking around developing 'digital interventions' predominantly adopts an incremental approach. We then discuss a gap in knowledge exemplified by the lack of radical-digital [29] interventions. In order to highlight the untapped potential of radical-digital technologies, we draw parallels from the rise of a 'sharing economy' [31] in the digital world and suggest that the elderly could benefit from being involved in it. We also propose that experimentation in this area can provide a provocative test-bed for HCI research in the third-paradigm [32].

\section{Mapping Loneliness Interventions}

According to cognitive theory of loneliness, loneliness can be manipulated; hence interventions have been developed to implement mitigation strategies [7]. These interventions mostly operate as services offering befriending, mentoring, information dissemination, etc. In their review, Windle et al. point out, "Just as the range of wellbeing services is extensive, so too is the available literature examining how well 
they work" [33]. Thus there are no standardised formulae that guarantee the success of loneliness interventions. The vast variety of interventions can broadly be classified as either being medical or non medical in their approach. Of the non-medical variety, many interventions operate as services that either provide companionship, information or support to the elderly and, in this paper, we focus on such non-medical interventions.

In order to highlight gaps in our existing understanding of how to prevent, reduce or alleviate age-related loneliness, we examined existing interventions in this area. The reviewed loneliness interventions were identified using an online ethnographic method. They were logged using a specially designed pattern recognition template and coding questions were developed to pigeonhole them into the following categories:
a. Incremental or Radical
b. Digital or Physical
c. Preventative, Supportive or Remedial
d. One to one, Group based or Community based

Using this method, all the interventions were logged onto the template, coded using the questions and mapped onto individual grids to arrive at a characteristic visualisation for each intervention ${ }^{1}$. All such individual visualisations were then transferred onto a single grid as shown in Figure 1 for analysis.

This early analysis of loneliness interventions has revealed a gap in research in the form of a lack of interventions that are 'radical' as well as digital in nature. The majority of the interventions we reviewed fall in the incremental-physical category. Before we begin to consider this gap further, it is important to unpack the meaning of 'radical' interventions. Manzini suggests that incremental innovations represent our existing ways of 'thinking and doing'. On the contrary, innovations that fall outside our current ways of 'thinking and doing' represent radical innovation [34]. Also, Norman and Verganti define incremental innovation as "improvements within a given frame of solutions" or "doing better what we already do" and radical innovation as "a change of frame" or "doing what we did not do before" [35]. This is akin to Dryzek's [36] 'reformist' versus 'radical' departures in environmental discourses. Reformist departures are similar to incremental approaches as they seek solutions within familiar modes of rational management, while radical departures argue for a comparatively significant movement away from industrial modes of living and being.

\footnotetext{
${ }^{1}$ Coding questions were developed in order to aid categorisation. The coding method has been discussed in detail in our previous work Radicalising the designer: Combating age-related loneliness through radical-digital interventions (in press) [29].
} 


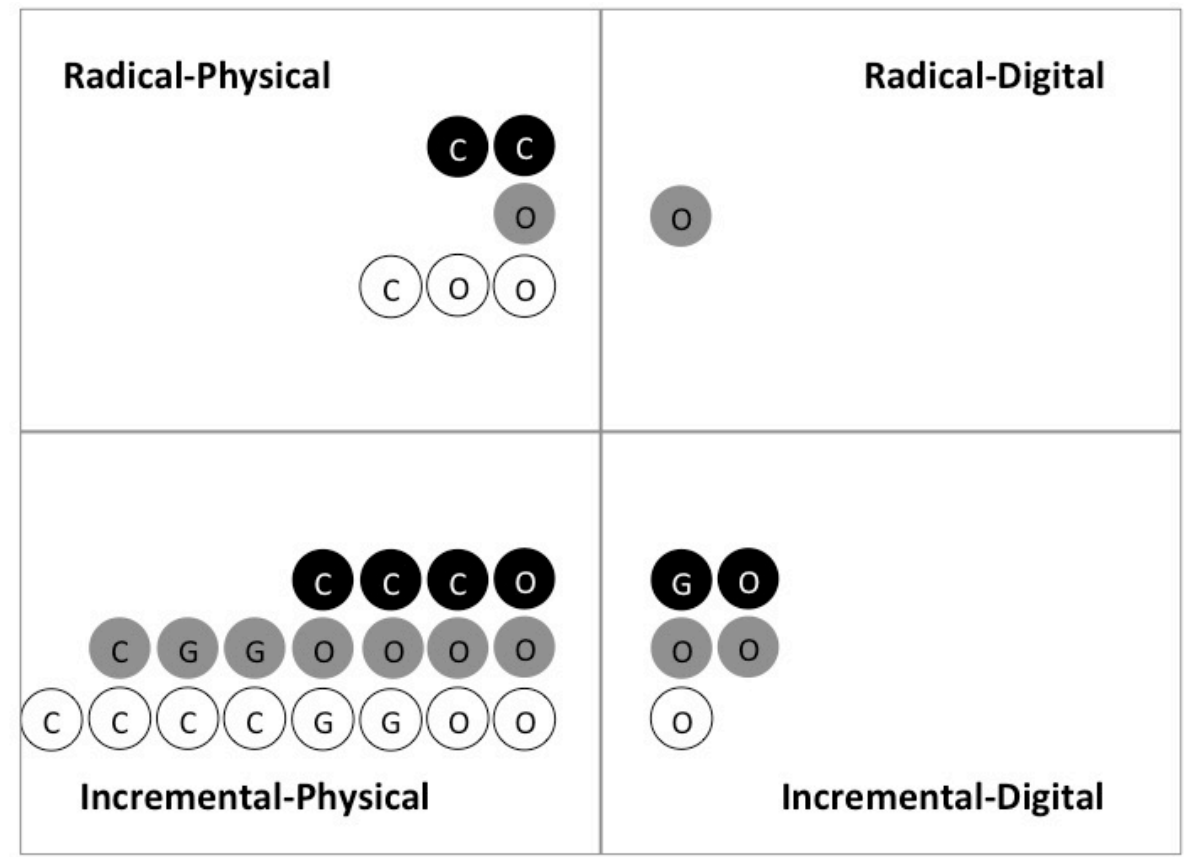

KEY

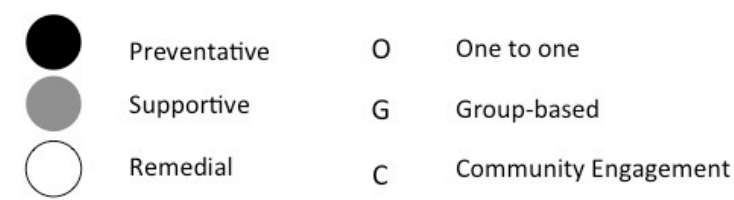

Fig. 1. Mapping all the interventions onto a single grid.

\section{Exploring Radical-Digital Interventions}

While radical-digital interventions may not, in the end, prove to be a 'silver-bullet' solution to the problem, the idea that they are underrepresented, as can be seen in the preliminary analysis, suggests that we do not know much about their potential strengths as well as possible weaknesses. An initial approach to exploring this opportunity could be to critically examine existing loneliness interventions in order to identify what separates the radical from the incremental and then finding ways of enabling their digitisation ${ }^{2}$. However a mere lack of the use of digital technologies in

\footnotetext{
${ }^{2}$ The Oxford Dictionary defines digitisation as "The conversion of text, pictures, or sound into a digital form that can be processed by a computer". Here we mean meeting the aims and objectives of radical interventions that are physical in nature by using digital technologies involving the elderly.
} 
developing loneliness interventions cannot be the sole justification for 'investing' in this area. Therefore this paper highlights the qualities that digital technologies possess, which can help in coping with challenges posed by old age. We begin by looking at key properties of ICT that could be of significant value in easing age-related challenges. We then look at digital loneliness interventions and suggest that they are predominantly incremental in nature. We point out that the growth of the online sharing economy [31] can provide a good framework to develop radical-digital interventions.

\subsection{Harnessing the digital}

Technological developments in the last decade or so have completely transformed the way we interact and communicate with each other. However a large proportion of older people seem to be neglected from this digital revolution. "Internet communication systems such as email and social networking sites like Facebook and Twitter have revolutionised personal communication for younger people. Government service provision is being transformed by technology, too, and many people are enjoying faster, easier access to public services through digital means. Not the over$65 \mathrm{~s}$, though: studies show that they have been largely excluded from this revolution and the benefits it brings. A startling 70\% report that they have never used the internet" [37]. Below we have discussed a few qualities of digital technologies that provide opportunities for bringing the potential benefits of ICT to the elderly.

\section{Ubiquity of digital technologies}

We live in a world today where the number of devices connected to the Internet is greater than the number of people on earth [38]. This ubiquity of digital technologies commonly known as 'Internet of Things' [39] has the potential to augment the outreach of care services developed for the elderly. Kraft and Yardley state that "the digital environment (e.g. Internet, mobile phones, smart phones) that is now an integral part of our daily lives is becoming an increasingly important means of sustaining the health of people worldwide, whether by providing access to a wealth of information, by linking geographically dispersed communities of peers and professionals, or by supporting self-management of health and illness" [40].

\section{Coping with mobility issues}

One of the main challenges posed by older age is its impact on mobility. Lack of mobility has also been identified as a precursor to loneliness amongst the elderly [41, 42] as it can limit their contact with their friends and family. O'Reilly argues that the Internet has all the features that should make it attractive to the elderly. For instance it lessens age-related mobility problems - transactions can be carried out from home, which is a relatively safe environment and majority of shopping can be done through a few clicks alone [43]. Recent research indicates that the use of digital technologies such as Skype, email and digital gaming [42, 44] can help the elderly keep in touch with their family and friends. Although this doesn't entirely replace the benefits of 
'embodied' communication, it is potentially beneficial as a coping strategy for those that suffer from lack of mobility due to age-related problems.

\section{Providing alternate infrastructure}

Recent socio-economic developments in the UK have severely impacted rural areas due to the closure of shops, post offices, bus routes, etc. [45]. By removing these 'social opportunities', this has impacted the quality of life of older people as they have become further isolated. It can be argued that the lack of a hard infrastructure can be negated by the use of a soft infrastructure. For example, farmers in rural India overcome the challenge of a lack of roads and transport facilities by using their mobile phones to settle their deals [46]. Although a different context, it still highlights the potential of using digital technologies in overcoming infrastructural challenges. Moreover digital technologies can be easily (and cheaply) modified, altered or customised in comparison to physical structures.

\section{Reframing perception of the 'elderly'}

Gaver et al. have pointed out that, "There is a kind of disciplinary hubris in the assumption that HCI (Human Computer Interaction) can define systems that reflect comprehensive understandings of users, whether in terms of tasks, problems or communities of use" [47]. The third paradigm challenges such predisposition as it elucidates the importance of use and usage of a system within context. Here we argue that loneliness interventions for the elderly based on social innovation fit within the sharing economy and that this creates a shared context that can provide an interesting opportunity to test ideas from the third paradigm in HCI.

\subsection{Social innovation in a digital world}

As introduced earlier, the majority of existing interventions are incremental and direct in their approach [29]. Someone is identified as lonely, therefore befriended or recommended to an expert service provider. These approaches focus on the underlying symptom of loneliness, i.e. the deficiency of human company, rather than a more holistic context such as envisioning a cultural milieu that nurtures meaningful human interactions.

A more radical approach can be found in the literature on social innovation, where the elderly are viewed as a desirable resource that has a unique offering that would be of benefit to society. Upon a closer examination of the interventions reviewed, we found that most of the radical interventions provide the elderly users something more than someone to speak to or the information they may require. With the exception of PARO, a robotic seal that brings the known benefits of animal therapy to elderly care, all the other radical interventions that were reviewed appear to treat the elderly as providers rather than as recipients alone. For example, the elderly have a crucial role to play in GoodGym. They provide the necessary motivation for keen runners to stay committed to running. Similarly, in Speaking Exchange, their role is not of a service 
user alone but it is one that entails offering support to help non-native English speakers brush up their English speaking skills. Homeshare is another great example where by giving someone a house to live-in, older people contribute to other peoples' wellbeing while being cared for simultaneously.

What these interventions actually provide the elderly is an opportunity to have a new role to play in the society, one where they can act as solutions to someone else's problems. Manzini encourages the idea of looking at problems as solutions to inspire Social Innovation [48]. Therefore by building loneliness interventions where the elderly person's role is not restricted to being a user of that service, but one where they can offer support or help to someone else, we can begin to create loneliness interventions that are radical. Such radical interventions can then move into the digital realm through the use of ICT.

\subsection{Social innovation in a sharing economy}

As Tonkinwise points out, sharing is something that we have always been doing in families, between friends, through government and with infrastructures [31] but more recently, the growth of the sharing economy has been propelled by the rise of Internet. "The ease with which individuals, even strangers, can now connect, exchange, share information, and cooperate is truly transformative. That's the promise of the sharing platforms about which virtually everyone agrees. But technologies are only as good as the political and social context in which they are employed. Software, crowdsourcing, and the information commons give us powerful tools for building social solidarity, democracy, and sustainability. Now our task is to build a movement to harness that power" [49].

Loneliness interventions based on social innovation are also closely associated with the sharing economy. Whether it is living in the same house in Homeshare, relying on a matching system to satiate seemingly unrelated personal objectives in GoodGym or sharing experiences online via Speaking Exchange, all these interventions rely on some form of a 'shared experience' to solve social problems. This suggests that social innovation can become a vehicle for encouraging older adults' involvement in the sharing economy. However, while we argue that the sharing economy combined with social innovation presents great potential to inspire the building of a framework for developing radical-digital loneliness interventions, if $70 \%$ of the target population have not used the Internet - access to the market requires an alternative strategy. The emergence of the third paradigm of HCI research provides a promising trajectory that this line of work could potentially benefit from.

\subsection{The third paradigm of HCI research.}

Harrison et al. begin their discussion of the third paradigm by recognising that embodied interaction is a 'key underlying' theme [32]. They opine that embodiment also plays an important role in other approaches to interaction. For instance, human factors practitioners pay attention to such aspects as the ergonomics of a mouse or the suitability of fonts and their sizes for specific purposes. They also suggest that 
cognitively based work in HCI focuses on physical constraints that guide interface design such as the speed at which humans react to a particular interface. They argue that embodiment in the third paradigm is based on a different stance. Seeking inspiration from phenomenology, "it takes as central that the way in which we come to understand the world, ourselves, and interaction derives crucially from our location in a physical and social world as embodied actors" [32]. In their review of embodiment in HCI research thus far, they bring to fore our fixation with visual, auditory and physical abilities of users. They argue that, "design can also support other senses and physical abilities such as action-centered skills and motor memory. Embodiment refocuses attention from the single-user/singe-computer paradigm that has recently dominated HCI towards collaboration and communication through physically shared objects" [32]. In his work on intergenerational digital games between grandparents and their grandchildren, Loos has also pointed out some of these issues in designing for shared experiences. He suggests that taking age-related factors such as declining vision, useful field of view, vision-motor ability and hearing is not sufficient for designing such games [44] and recommends a more 'humancentred research procedure' in the form of workshops involving both younger and older adults to capture mutual expectations from such games.

As HCI researchers, if we are to design for such joint experiences, then the third paradigm becomes extremely relevant as it emphasises the importance of users 'situated' [50] within their contexts. In case of loneliness interventions based on social innovation, users' contexts are shared ones. Therefore skills with a social science lineage which inherently study people in their contexts, such as ethnography, ethnomethodology and sociology, etc. might gain a more prominent place in relation to other approaches such as human factors and usability research which presently occupy more space in a HCI practitioner's toolbox.

Dillahunt points out that "technological platforms and applications that promote the sharing economy (e.g. AirBnB, TaskRabbit), and job creation (e.g. oDesk, MTurk), and trading (e.g. Craigslist) are relatively understudied within HCI" [51]. Therefore we imply that HCI community would benefit from an engagement with the elderly population prone to loneliness, as it would allow for experimentation within the rapidly evolving sharing economy space in the backdrop of the third paradigm.

\section{Conclusion}

This paper discusses the social problem of loneliness, which is increasing amongst older people as an unprecedented number of people are beginning to reach retirement age globally. We have examined our existing approach to mitigating loneliness through non-medical interventions. Our review reveals that the predominant tactic we deploy in alleviating loneliness is incremental-physical in nature. We identify a gap in this area in the form of lack of radical-digital interventions and advocate experimentation in this area to uncover their strengths and / or possible limitations. 
We present key properties of digital technologies that can help in coping with agerelated challenges. For instance, ubiquity of digital technologies, their ability to negate the challenge of mobility presented by old age and their disposition as a potential substitute for hard infrastructure. We suggest that social innovation provides a compelling theoretical framework to develop radical interventions and that the use of ICT can potentially enhance their impact. By highlighting the similarities between loneliness interventions based on social innovation and the rapidly evolving 'sharing economy', we recommend that developing such interventions provides a great foundation for HCI research into shared experiences. We conclude by positing that the HCI community would benefit from looking into the third paradigm for inspiration on how to plan and execute research for such shared experiences.

\section{References}

1. Hughes, M.E., et al., A Short Scale for Measuring Loneliness in Large Surveys Results From Two Population-Based Studies. Research on Aging, 2004. 26(6): p. 655-672.

2. Weiss, R.S., Loneliness: The experience of emotional and social isolation. 1973.

3. Cacioppo, J.T., L.C. Hawkley, and R.A. Thisted, Perceived social isolation makes me sad: 5-year cross-lagged analyses of loneliness and depressive symptomatology in the Chicago Health, Aging, and Social Relations Study. Psychology and aging, 2010. 25(2): p. 453.

4. Perlman, D. and L.A. Peplau Loneliness. 1998.

5. Pinquart, M., Loneliness in married, widowed, divorced, and never-married older adults. Journal of Social and personal relationships, 2003. 20(1): p. 31-53.

6. Lynch, J.J., The broken heart: The medical consequences of loneliness. 1977: Basic Books New York.

7. Cattan, M., et al., Preventing social isolation and loneliness among older people: a systematic review of health promotion interventions. Ageing and society, 2005. 25(01): p. 41-67.

8. Stuart-Hamilton, I., The psychology of ageing: An introduction. 2012: Jessica Kingsley Publishers.

9. Waal, F.B.M., Our Inner Ape: The Best and Worst of Human Nature. 2006: Granta.

10. Leikas, J., et al., Life-based design to combat loneliness among older people. The Journal of Community Informatics, 2012. 8(1).

11. Havinghurst, R., Ageing in western society. The Social Challenge of Ageing. London: Croom Helm, 1978: p. 15-44.

12. Hunt, A., The Elderly at Home-a Study of People Aged 65 and Over Living in the Community in England 1976. 1978: HM Stationery Office.

13. Wenger, G.C., Loneliness: a problem of measurement. Ageing in modern society, 1983: p. 145-167.

14. Beaumont, J., Measuring National Well-being - Older people and loneliness. 2013, Office for National Statistics, UK.

15. Rutherford, T., Population ageing: statistics, in House of Commons library (Standard not. Retrieved Jan 2, 2013, from: www. parliament. uk/topics/PopulationArchive. 2012, Social and General Statistics. 
16. Cacioppo, J.T. and W. Patrick, Loneliness: Human nature and the need for social connection. 2008: WW Norton \& Company.

17. Dychtwald, K. and J. Flower, Age wave: The challenges and opportunities of an aging America. 1989: Bantam Books.

18. O'Connor, J. Age-related loneliness is a ticking time bomb waiting to explode. Inside Time: the National Newspaper for Prisoners and Detainees 2014 [cited $2014 \quad$ September]; Available from: http://insidetime.co.uk/articleview.asp? $\mathrm{a}=1773 \& \mathrm{c}=$ agerelated_loneliness_is_a_tick ing_time_bomb_waiting_to_explode.

19. Sheldon, J.H., The Social Medicine of Old Age. Report of an Enquiry in Wolverhampton. The Social Medicine of Old Age. Report of an Enquiry in Wolverhampton., 1948.

20. Halmos, P., Solitude and privacy: a study of social isolation its causes and therapy. Vol. 15. 1998: Psychology Press.

21. Dykstra, P.A., T.G. Van Tilburg, and J. de Jong Gierveld, Changes in Older Adult Loneliness Results From a Seven-Year Longitudinal Study. Research on aging, 2005. 27(6): p. 725-747.

22.Dykstra, P.A., Older adult loneliness: myths and realities. European journal of ageing, 2009. 6(2): p. 91-100.

23. Kaasa, K., Loneliness in old age: Psychosocial and health predictors. Norsk epidemiologi, 1998. 8(2).

24. Demakakos, P., S. Nunn, and J. Nazroo, 10. Loneliness, relative deprivation and life satisfaction. Retirement, health and relationships of the older population in England, 2006: p. 297.

25. Hawkley, L.C. and J.T. Cacioppo, Aging and Loneliness Downhill Quickly? Current Directions in Psychological Science, 2007. 16(4): p. 187-191.

26. Kim, O., et al., Loneliness, depression and health status of the institutionalized elderly in Korea and Japan. Asian Nursing Research, 2009. 3(2): p. 63-70.

27. Marsh, S. Fourteen ways councils can help combat loneliness. Public Leaders Network: Insight, news, comment and jobs in policy and leadership 2014 [cited 201414 September]; Available from: http://www.theguardian.com/localgovernment-network/2014/apr/14/fourteen-ways-councils-can-help-combatloneliness.

28. Murphy, F., Loneliness: a challenge for nurses caring for older people. Nursing older people, 2006. 18(5): p. 22-25.

29. Sharma, D., L. Blair, and S. Clune, Radicalising the designer: Combating agerelated loneliness through radical-digital interventions, in Cumulus: Virtuous Circle. 2015: Milan, Italy.

30. Gaver, W.W. Technology affordances. in Proceedings of the SIGCHI conference on Human factors in computing systems. 1991. ACM.

31. Tonkinwise, C. Unpredictable Conveniently Awkward Sharing. 2015 [cited 2015 15 February 2015]; Available from: https://www.academia.edu/10605747/What_Futurists_should_learn_from_the_Inco nvenience_of_Sharing.

32. Harrison, S., P. Sengers, and D. Tatar, Making epistemological trouble: Thirdparadigm HCI as successor science. Interacting with Computers, 2011. 23(5): p. 385-392. 
33. Windle, K., J. Francis, and C. Coomber, Preventing loneliness and social isolation: interventions and outcomes. London: Social Care Institute for Excellence, 2011: p. 1-16.

34. Manzini, E. and DESIS Network, Making things happen. DesignIssues, 2014. 30(1): p. 57-66.

35. Norman, D.A. and R. Verganti, Incremental and Radical Innovation: Design Research vs. Technology and Meaning Change. Design Issues, 2014. 30(1): p. 7896.

36. Dryzek, J.S., The politics of the earth: Environmental discourses. 2005: Oxford University Press.

37. Independent Age. Older People, Technology and Community: The Potential of Technology to Help Older People Renew or Develop Social Contacts and to Actively Engage in Their Communities. 2010 [cited 201516 February]; Available from: http://www.cisco.com/web/about/ac79/docs/wp/ps/Report.pdf.

38. Frey, T. Replacing Our Physical Infrastructure with Digital Infrastructure. FuturistSpeaker.com: Challenging your thinking, pushing your imagination, creating the future 2012 [cited 201516 February]; Available from: http://www .futuristspeaker.com/2012/11/replacing-our-physical-infrastructurewith-digital-infrastructure/.

39. Das, R. and P. Harrop, The Internet of Things: massive new markets for automated location, tracking, authentication and barcode replacement. Total Asset Visibility, IDTechEx Ltd, 1999.

40. Kraft, P. and L. Yardley, Current issues and new directions in Psychology and Health: What is the future of digital interventions for health behaviour change? 2009.

41. Milligan, C. and D. Passey. Ageing and the use of the internet: Current engagement and future trends. 2011 [cited 201516 February 2015]; Available from: http://www.nominettrust.org.uk/sites/default/files/NT\%20SoA\%20$\%$ 20Ageing\%20and\%20the\%20use\%20of\%20the\%20internet_0.pdf.

42. Age UK. Digital inclusion evidence review. 2013 [cited 201516 February]; Available from: http://www.ageuk.org.uk/Documents/EN-GB/Forprofessionals/Research/Age\%20UK\%20Digital\%20Inclusion\%20Evidence\%20Re view\%202013.pdf?dtrk=true.

43. O'Reilly, P. Use of Internet Banking by the Elderly - time to rise to the challenge. $2008 \quad$ [cited $2015 \quad 16 \quad$ February]; Available from: https://www.researchgate.net/researcher/2014977975_Paidi_OReilly.

44.Loos, E. Designing meaningful intergenerational digital games. in International Conference on Communication, Media, Technology and Design. 2014.

45. Commission for Rural Communities. Social isoltion experienced by older people in rural communities. 2012 [cited 201516 Februrary]; Available from: http://www .agenda-efa.org.uk/site/wp-content/uploads/2012/09/ExecutiveSummary-Social-isolation-experienced-by-older-people-in-rural-communities.pdf.

46. The Centre for Knowledge Societies, Mobile Development Report. 2006: India.

47. Gaver, W., et al. The prayer companion: openness and specificity, materiality and spirituality. in Proceedings of the SIGCHI conference on Human factors in computing systems. 2010. ACM. 
48. Association, I.D. Ezio Manzini-Keynote: Design for Social Innovation and Sustainability. 2010 [cited 201401 September]; Available from: http://vimeo.com/9660466.

49. Schor, J. Debating the Sharing Economy. Great Transition Initiative: Toward a transformative vision and praxis 2014 [cited 201517 February]; Available from: $\mathrm{http}$ //greattransition.org/publication/debating-the-sharing-economy.

50. Suchman, L.A., Plans and situated actions: the problem of human-machine communication. 1987: Cambridge university press.

51. Dillahunt, T. Toward a deeper understanding of sustainability within HCI. 2014. CHI. 